\title{
Transforming the ACPSEM for a sustainable future
}

\author{
Ian Smith ${ }^{1}$
}

Published online: 8 March 2016

(C) Australasian College of Physical Scientists and Engineers in Medicine 2016

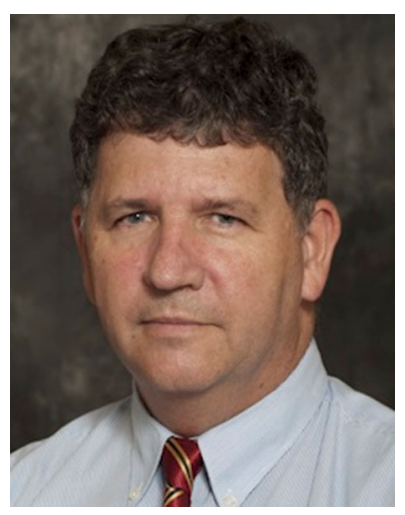

This is my second stint on council having previously served as Branch Chair (Qld/NT) in 1996/1997 and then Honorary Treasurer from 1998 to 2004. At that time the ACPSEM was run exclusively by volunteer members, with council not only charged with providing professional and strategic direction for the college but also having full responsibility for the day to day aspects of its operation. Towards the end of this first phase on council, however, things had started to change. The efforts of some of my illustrious predecessors and the teams they worked with was beginning to bear fruit and the ACPSEM had been successful in obtaining government grant funding to develop a more professional approach to the training and certification of physicists working in radiation oncology. One of my last responsibilities as treasurer was to participate in processes leading to the appointment of the first

Ian Smith

ian.smith@uchealth.com.au

1 University of Cincinnati Physicians Company (UCPC), Cincinnati, OH, USA
ACPSEM employees and the establishment of an ACPSEM 'office'.

Coming back onto council in 2014, after almost a decade's absence, has given me the opportunity to experience first hand the tremendous expansion in services (particularly training) that has taken place. With a professionally staffed and managed office in place to handle administrative and operational matters, council (now the board) is free to focus on strategic and professional issues.

However, it is important to evaluate the means by which we have been able to grow and to understand what we need to do to safeguard the continued operation of the ACPSEM at these levels. These challenges are not new, and in fact were foreshadowed by a number of my predecessors, particularly those involved in securing the first grants. A review of the last financial statement I delivered as treasurer in 2004 showed we had a total income of just over $\$ 100 \mathrm{k}$ (40\% from membership fees) with net assets of $\$ 180 \mathrm{k}$. In stark contrast, the current position outlined in the last treasurer's report places the 2015 ACPSEM income at close to $\$ 1.5 \mathrm{M}$ (with net assets of $\$ 1.3 \mathrm{M})$. Exploring a little further into these numbers reveals that around $60 \%$ of this income is derived from government funding while membership fees represent only $14 \%$ of the total.

And herein is the challenge, and what I see as the objective for my period as president, how does the ACPSEM transition to a sustainable future? To achieve this objective I believe we need to focus our efforts in three main areas:

Structural: Modernize the structural aspects of the ACPSEM to remove impediments to operation and growth. While a key component of this involves revision of the Constitution (and associated processes and 
procedures) we also need to explore ways of improving communication with and the engagement of our members. In particular we need to rethink the way specialty groups work which might look at the adoption of more modern approaches such as the concept of 'Communities of Practice' to encourage collaboration across the breadth of the ACPSEM areas of interest

Functional: Refocus the 'purpose' of the ACPSEM from what has developed into a predominantly training role to one that supports a broader education (whole of career) agenda. This will also, by necessity, have an impact on the role of the specialty groups, which have a key role in driving leadership in our professional space

Financial: Stabilise and secure the financial underpinnings of operation through a reduced dependence on grant funding. To achieve this we will need to review both how we use our resources and seek opportunities to broaden our income base

As part of the first council meeting held in February 2015, the committee undertook a review of the ACPSEM's key strategic goals with a view to setting the agenda for work across the 4 years from 2015 to 2018. Out of the work done, we were able to distill goals covering four key areas:

Sustainability and funding

- Fulfil DOH grant requirements

- Provide framework to guide expanded program development

Communications

- Targeted communications

- Demonstrate leadership of the professions

- Website improvement

- Improve communications capabilities

Education

- Expand to whole of career

- Professional development and training programs

- CPD online facilities

Membership

- Increase numbers from current base

- Expand to like professions

- Membership communications plan

Although listed under separate headings, the reality is that these goals are strongly interwoven, with success in each being dependent upon and contributing into the success of others. It is also important to note that these goals cover the Structural, Functional and Financial areas of focus identified as being the key areas we need to address in order to achieve a more secure future.
Rather than discuss each in detail, I would like to highlight three project areas to illustrate the body of work being done in the short term (within the next year), mid term (within 2 years) and longer term.

\section{Constitution review}

The first major project concerns the Constitution Review. Although this was voted on and approved at the AGM in Wellington, this was not the end of this component of work but merely the start of an intense program of reviewing and redrafting all of the documents that 'control' the day-to-day operation of the ACPSEM. Although I have flagged this project as being one that is set for completion within the next 12 months, the reality is the timeline requires substantial completion by mid 2016 so that we can commence the process of electing the board members for 2017. This is an important project that has to be done to set the foundation for much of the work required to secure the future of the ACPSEM.

Completion of the constitution review delivers governance processes that align with current practices to ensure efficient and effective leadership of the ACPSEM based on clearly defined direction and values. A key outcome of this project is that it allows us to design and implement processes that will optimise volunteer participation in governance. Finally, the revised governance processes remove unnecessary restrictions on the ability of ACPSEM to deliver future strategies and operations.

A central feature of the new governance structure is a smaller board, comprising eight elected ACPSEM members and one external board member who can be appointed to provide specialist input into an area of responsibility of the board deemed to be of most importance. It may be that currently this will be in the financial management area. This smaller board structure will improve communication between the board members and will allow it to focus on strategic matters, particularly, sustainability, membership services and professional standing.

\section{Specialty groups}

The second project I would like to highlight concerns the specialty groups. This is a project I would like to see undertaken within the next 2 years. Under the new constitution the specialty groups will have an ongoing responsibility through participation in the Advisory Forum. As such, it is essential that these groups be in a position to discharge their required functions.

The specialty groups were established 'to provide a strong, cohesive driving force for the management of each 
discipline's respective profession'. They are intended to provide proper professional standards of work and safe practice for the benefit of the public and the environment. In doing their work they have two roles. The first is a Reactive Role in which they are required to provide responses to approaches for comment and review of new standards, legislation and other professional materials. The second role is a Proactive Role where it is expected that the groups would actively pursue leadership in the profession, for example generate position papers and drive standards.

As vice president, I served 2 years as chair of the Heads of Specialties group. Through this role it became apparent that the groups, as a whole, are struggling to complete projects or be seen to be producing results. In no way is this comment meant as a criticism of those that have taken on these roles. One of the issues here is that the groups seem to suffer from a lack of available volunteers when requests are made for input. This may be an indication of the level of stress we all feel in our day to day work; however, it is important for our professional standing that when we receive requests for comment, that we make the effort to provide some kind of reasoned response to ensure we remain relevant to the profession. This is usually not a matter the office can do in isolation: we are the technical experts and we are the ones that have to do the work.

Part of the concern is that the conventional specialty group process may not be the right mechanism in the modern context. It may not be the best way of reflecting the needs of members or the way members want to contribute. We have spent considerable time over the last 12 months gaining an understanding of what members expect from the ACPSEM. This is a very important process as it will provide some ideas on how the specialty groups can best operate.

As stated at the start of this commentary, the goals identified in the strategic review are not represented by discrete, isolated projects and this is one example.

One of the objectives identified in the strategic review concerns providing members with whole of career support. It could be argued that substantial effort to date has focused on addressing the needs of those at the start of their career, with this having a flow on benefit to those in the later phases of their careers in senior or management positions by ensuring a reliable source of appropriately trained and qualified staff.

A concern is that this focus has come at the potential expense of those in the middle of their careers. This is the cohort of members that potentially have a need for career development; this is the cohort of members that need to be driving the ACPSEM's professional agenda going forward, this is the cohort of people that need to be engaged in the activities of the specialty groups.
A key mechanism introduced through the new Constitution to support operation of the board is the Advisory Forum. This group, comprising representatives of the specialty groups, Professional Standards Board and Branches will meet at least once a year to thrash out important issues relevant to the operation of the ACPSEM. A key role for this group is to advise the board on professional matters and strategy. In this capacity, one of the first tasks of the Advisory Forum may be to take a lead role in reshaping the specialty groups.

\section{Sustainability and funding}

The third project area I would like to touch upon concerns financial sustainability. Although I have indicated that this is a long term project, the reality is that work on securing sustainability has been going on for some time and is a constant thought in the minds of those working on the board.

A review of the 2014/2015 Director's Report shows that in broad terms, the ACPSEM requires approximately $\$ 1.5 \mathrm{M}$ in income each year to support its operation. Presently around $30 \%$ of this income is derived from fees (membership $\sim 14 \%$, accreditation $\sim 3 \%$ and TEAP $\sim 12 \%$ ). Although we generate about $10 \%$ of our income from conferences, courses and other sources it is of major concern that we are still reliant upon government grants for around $60 \%$ of our income. This had been as high as $75 \%$ a few years ago.

Having a dependence on any single source of income of more than $40 \%$ is seen as being a potential issue for survival so a major strategic objective is to reduce dependence on government grants by diversifying and growing income in other areas. Modern governance would suggest that having three or more sources of revenue at $20 \%$ or higher helps associations improve sustainability. A diversified funding stream will also ensure that operation of the ACSEPM is not dominated by the need to deliver services in one particular area or cause the ACPSEM to prioritize one group of members over the interest of others to satisfy specific funding requirements.

Again, all of these projects must be viewed as interwoven, revision of the constitution will allow us the opportunity to expand our focus, review of the specialty groups based on membership expectations will provide key information on how best to serve the membership and this in turn may lead to expansion of the membership base.

So, the board and office is working on a multi pronged approach to securing our financial future. In essence, these efforts are directed in three areas.

First and foremost it is imperative that we deliver on the terms of our grant funding agreements. This is absolutely 
essential. The only way we can hope to secure new funding through these channels in the future is to providing convincing evidence that we are using what funds we are provided wisely and effectively.

The next strategy is around increasing the absolute number of members. In any business, the efficiency of fixed cost components is enhanced by spreading those costs across a broader base. One avenue for this is though increasing the coverage of current professions catered for by the ACPSEM. This can potentially be achieved by ensuring that we provide the type of services that attract and retain our members and providing members with better representation at government and associated profession levels. We can also ensure that we work to create a need for the service provided by our members. Another opportunity is to explore expansion of the scope of membership to other like professions. The recent inclusion of the Radiopharmaceutical Scientists is an example of what is possible in this regard.

The third strategy is to expand the revenue base by increasing the contribution of a number of existing services we provide. This would see us place a financial expectation on conferences to return a more significant surplus. Another approach is to leverage off the training material and processes we have developed and expand these to other markets or professional areas of activity.

\section{Conclusion}

Although the ACPSEM is currently in a sound position, the board and office are not resting on their laurels. We have a plan in place that is regularly reviewed; that we believe will lead us to a more secure future. However, no matter how well we plan for the future, it is the engagement of the membership that will be the difference in whether we, as a whole, succeed or not. So when the opportunity presents itself to contribute to the operation of the ACPSEM and provide your input into shaping its future, please take the time to be actively involved.

Ian Smith

President ACPSEM 